\title{
Correlation between resilience and social support and anxiety in obstetric nurses ${ }^{\dagger}$
}

Original article

\author{
Xiao-Xi Liua, Wei-Hua Liua,*, Ma Ping ${ }^{b}$, Cheng-Yao Lic ${ }^{\text {, }}$ Xiao-Ying Liu a ${ }^{a}$ Ping Song ${ }^{a}$
}

${ }^{a}$ School of Nursing, Taishan Medical University, Taian, Shandong 271016, China

${ }^{b}$ Healthcare Department, Laiwu Traditional Chinese Medicine Hospital, Laiwu, Shandong, China

'Operation Room, Shandong Cancer Hospital, Ji'nan, Shandong, China

Received: 11 October 2017; Accepted: 8 January 2018; Published: 20 December 2018

\begin{abstract}
Objective: The aim of this study was to explore the correlation between psychological resilience and social support and anxiety in obstetric nurses and to provide theoretical basis for improving the mental health of obstetric nurses.

Methods: In this study, 190 obstetric nurses were included, using the general information questionnaire and The Connor-Davidson Resilience Scale (CD-RISC), Social Support Rating Scale, and survey of Self-evaluation of Anxiety Scale.

Results: There are differences in the type of work and the score of psychological resilience $(P<0.05)$, obstetric nurses' resilience score was $65.58 \pm 10.65$; self-rating anxiety score of obstetric nurses was $36.89 \pm 6.87$; and social support score of obstetric nurses was 44.37 \pm 7.86 . The psychological elasticity score and anxiety were negatively related $(P<0.01)$, whereas the resilience score and tota score of social support were positively related $(P<0.01)$.

Conclusions: Obstetric nurses have many responsibilities and stress. Nursing managers should focus on obstetric nurses' mental health, lighten the obstetric nurses' anxiety, and thus improve their mental flexibility and optimize the quality of nursing service better, with more passion into work.
\end{abstract}

Keywords: obstetrics $\bullet$ nurses $\bullet$ psychological elasticity $\bullet$ social support $\bullet$ anxiety

(c) Shanxi Medical Periodical Press.

\section{Introduction}

Obstetric nursing is a nursing specialty that takes care of pregnant women who have quick maternal changes and emergency situations to the health of both mother and child along with China's family planning policy to be involved in the whole society of family health-care services, resulting in long-term obstetric nurses' stress and high work load condition. ${ }^{1}$ In clinical work, psychological pressure is relatively more generally in clinical nursing staff, ${ }^{2}$ and resilience is a trait or ability to face the pressure an individual is in the face of adversity,

${ }^{\top}$ This study was supported by The National Social Science Fund of China (No. 15BRK023).

* Corresponding author.

E-mail: liuwei8092@126.com (W.-H. Liu). trauma, disaster, and other great life pressure, and good development of the successful adaptation of ${ }^{3-5}$ resilience is even considered 6 one of the important factors that nurses should adapt during physiological and psychological pressure in nursing activities, especially in the nursing profession. Social support as a protective factor of resilience of the most important individual in alleviating the pressure eliminates the psychological barriers, promotes the individual's mental health, and plays an important role, ${ }^{7}$ and research shows that social support and mental health are positively correlated; social support can predict individual's health level. ${ }^{8}$ In recent years, China began to study nursing work pressure, but the research on the psychological pressure of obstetric nurses is rare, and with resilience as a positive psychological quality, able to buffer the stress caused

D Open Access. (c) 2018 Xiao-Xi Liu et al., published by Sciendo. (c) BY-NC-ND This work is licensed under the Creative Commons Attribution NonCommercial-NoDerivatives 4.0 License. 
by the negative impact, ${ }^{9}$ this study aimed not only to understand the obstetric nurses' resilience, social support, and anxiety status in order to reduce the degree of anxiety and improve the work efficiency and the level of mental health but also provides theoretical basis for the study of resilience on the report as follows.

\section{Subjects and methods}

\subsection{Subjects of the study}

In May 2017, 190 nurses from three hospitals in Tai'an were selected by the convenient sampling method. Inclusion criteria are as follows: registered nurses; nurses in obstetrics nursing work for more than 1 year; and the willingness to participate in this study.

\subsection{Research method}

The method of questionnaire investigation was used in this study; unified questionnaires were provided to the nursing department. The nurses were asked to truthfully fill out the questionnaire according to the instructions, and at the day of recovery, a total of 190 questionnaires were distributed; of those, 183 questionnaires were recovered, with an effective recovery rate of $96.3 \%$.

\subsection{Research tool}

\subsubsection{General information questionnaire}

Some researchers have designed the questionnaire themselves according to the purpose of the study, including age, education, title, position, number of years in obstetrics, type of work, and so on.

\subsection{2. $C D-R I S C$}

CD-RISC includes 25 items, each with five items of the questionnaire for self-evaluation as follows: 0 is able to do so; 1 is divided into two occasionally do; in general can be divided into three parts; can be divided into 4; be complete, and the total score is $0-100$. The higher the score, the higher the level of psychological toughness. CD-RISC has good reliability and validity, and its clonal Baja coefficient is $0.89 .{ }^{10}$

\subsubsection{Self-Rating Anxiety Scale ${ }^{11}$}

Based on the Zung Self-Rating Anxiety Scale compiled in 1971, a total of 20 questions (15 questions for positive evaluation and five questions for reverse evaluation) with a score of $1-4,1$ points for the few, 2 people sometimes, 3 points for most of the time, and most of the time is divided into 4 were asked to evaluate the subjective feelings of the patients. The sum score of 20 questions to the total score, standard score ( $Y=$ score of 1.25 after rounding), score $>50$ has a tendency of anxiety, the higher the score, the more obvious tendency of anxiety.

\subsubsection{Social Support Rating Scale ${ }^{12}$}

Equal to 1980 s compiled by Xiao Shuiyuan, including the three dimensions (objective support, subjective support, and utilization of support) a total of 10 items, with 1-4 grade score, total score of social support score, score 66 points, the lowest score was 12 points, the higher the score is, the higher level of social support. The score of $<20$ means low social support, 20-30 means general social support, and $>30$ means high social support. The scale was applied to a number of domestic studies with good reliability and validity. The test-retest reliability was 0.92 , and the consistency of each item was from 0.89 to 0.94 .

\subsection{Statistical method}

After all the data were audited, a database was set up and analyzed by SPSS 23.0 software, including descriptive statistics analysis, variance analysis, $t$-test, correlation analysis, and regression analysis.

\section{Results}

\subsection{General information}

All the 183 finally enrolled nurses (female, aged 20-50 years; mean $34.1 \pm 7.24$ years) engaged in obstetric care for $1-26$ years (average $8.26 \pm 6.72$ years) and other basic conditions were included in this study (Table 1 ).

\begin{tabular}{lcc}
\hline Characteristics & $\begin{array}{c}\text { Number of } \\
\text { people }(n)\end{array}$ & $\begin{array}{c}\text { Constituent } \\
\text { ratio }(N / n \%)\end{array}$ \\
\hline \hline $\begin{array}{l}\text { Age (years) } \\
<30\end{array}$ & 76 & 41.4 \\
$31-40$ & 69 & 37.8 \\
$>41$ & 38 & 20.6 \\
Education & 15 & \\
$\quad$ Secondary specialized & & 8.2 \\
school & 60 & 32.8 \\
Junior college & 106 & 57.9 \\
$\quad$ Undergraduate & 2 & 1.1 \\
$\quad$ Master degree or above & & \\
\hline
\end{tabular}

Table 1. Basic situation of obstetric nurses $(n=183)$. 


\begin{tabular}{lcc}
\hline Characteristics & $\begin{array}{c}\text { Number of } \\
\text { people }(n)\end{array}$ & $\begin{array}{c}\text { Constituent } \\
\text { ratio }(N / n \%)\end{array}$ \\
\hline \hline Positional titles & 49 & 26.8 \\
$\quad$ Nurse & 83 & 45.4 \\
$\quad$ Primary nurse & 47 & 25.7 \\
$\quad$ The nurse in charge & & \\
$\quad$ Deputy director of the & 4 & 2.2 \\
nurse & & \\
Post & 163 & 89.1 \\
Nurse & 20 & 10.9 \\
Head nurse & 49 & \\
Engaged in obstetric nursing work (years) & 26.8 \\
1-5 & 50 & 27.3 \\
5-10 & 39 & 21.3 \\
11-15 & 21 & 11.5 \\
16-20 & 24 & 13.1 \\
>20 & & \\
Work type & 75 & 41.0 \\
On regular payroll & 104 & 56.8 \\
Contract & 4 & 2.2 \\
Personnel agency & & \\
\hline
\end{tabular}

Table 1. (Continued)

\subsection{Scores of various levels of resilience in obstetric nurses (Table 2)}

\begin{tabular}{llc}
\hline Items & \multicolumn{1}{c}{ Dimensions } & Scores \\
\hline \hline Resilience scale & Personal ability & $17.52 \pm 4.36$ \\
& Sense of control & $18.44 \pm 4.40$ \\
& Spiritual influence & $4.70 \pm 1.50$ \\
& Endure negative emotions & $10.48 \pm 2.18$ \\
& Accept changes & $14.00 \pm 2.89$ \\
& The total score & $65.58 \pm 10.65$ \\
Self-rating scale & Positive scoring & $24.07 \pm 6.49$ \\
& Reverse scoring & $12.80 \pm 3.50$ \\
Social Support & The total score & $36.89 \pm 6.87$ \\
Rating Scale & Subjective support & $26.03 \pm 4.59$ \\
& Objective support & $11.75 \pm 3.01$ \\
& Utilization of support & $8.43 \pm 1.91$ \\
& The total score & $44.37 \pm 7.86$ \\
\hline
\end{tabular}

Table 2. Scores of dimensions of resilience scale of obstetric nurses (mean $\pm \mathrm{SD}$ ).

\subsection{Scores of anxiety self-rating scale in obstetric nurses (Table 3)}

\begin{tabular}{lc}
\hline Dimensions & Scores \\
\hline \hline Positive scoring & $24.07 \pm 6.49$ \\
Reverse scoring & $12.80 \pm 3.50$ \\
The total score & $36.89 \pm 6.87$ \\
\hline
\end{tabular}

Table 3. Scores of anxiety self-rating scale in obstetric nurses (mean $\pm \mathrm{SD}$ ).

\subsection{Scores of Social Support Rating Scale for obstetric nurses (Table 4)}

\begin{tabular}{lr}
\hline Dimensions & \multicolumn{1}{c}{ Scores } \\
\hline \hline Subjective support & $26.03 \pm 4.59$ \\
Objective support & $11.75 \pm 3.01$ \\
Utilization of support & $8.43 \pm 1.91$ \\
The total score & $44.37 \pm 7.86$ \\
\hline
\end{tabular}

Table 4. Dimensions of social support dimensions of obstetric nurses (mean \pm SD)

\subsection{Analysis of the difference of resilience among obstetric nurses in general population data}

The 183 obstetric nurses' age, education, work experience, job title, the type of single factor variance analysis engaged in, differences in the type of work, and the score of psychological resilience were analyzed $(P<0.05)$, and the difference was statistically significant (Table 5).

\begin{tabular}{|c|c|c|c|c|}
\hline Characteristics & Number & $\begin{array}{c}\text { Score } \\
(\text { mean } \pm S D)\end{array}$ & $F$ & $P$ \\
\hline \multicolumn{5}{|l|}{ Age (years) } \\
\hline$<30$ & 76 & $66.20 \pm 10.77$ & & \\
\hline $30-40$ & 69 & $66.92 \pm 12.94$ & & \\
\hline \multirow[t]{2}{*}{$>40$} & 38 & $66.05 \pm 13.73$ & & \\
\hline & & & 0.88 & 0.915 \\
\hline \multicolumn{5}{|l|}{ Education } \\
\hline \multicolumn{5}{|l|}{$\begin{array}{l}\text { Secondary } \\
\text { specialized school }\end{array}$} \\
\hline Junior college & 60 & $68.23 \pm 11.63$ & & \\
\hline Undergraduate & 106 & $64.93 \pm 12.06$ & & \\
\hline \multirow[t]{2}{*}{$\begin{array}{l}\text { Master degree or } \\
\text { above }\end{array}$} & 2 & $82.50 \pm 6.36$ & & \\
\hline & & & 2.232 & 0.086 \\
\hline \multicolumn{5}{|l|}{ Positional titles } \\
\hline Nurse & 49 & $64.06 \pm 11.90$ & & \\
\hline Primary nurse & 83 & $66.96 \pm 11.68$ & & \\
\hline The nurse in charge & 47 & $68.78 \pm 12.87$ & & \\
\hline \multirow[t]{2}{*}{$\begin{array}{l}\text { Deputy director of } \\
\text { the nurse }\end{array}$} & 4 & $57.25 \pm 14.00$ & & \\
\hline & & & 2.042 & 0.110 \\
\hline \multicolumn{5}{|l|}{ Post } \\
\hline Nurse & 163 & $66.34 \pm 12.13$ & & \\
\hline \multirow[t]{2}{*}{ Head nurse } & 20 & $67.25 \pm 13.10$ & & \\
\hline & & & 0.177 & 0.675 \\
\hline \multicolumn{5}{|c|}{ Engaged in obstetric (years) } \\
\hline $1-5$ & 49 & $65.56 \pm 10.27$ & & \\
\hline $5-10$ & 50 & $66.52 \pm 10.64$ & & \\
\hline $11-15$ & 39 & $68.92 \pm 15.28$ & & \\
\hline $16-20$ & 21 & $67.19 \pm 12.89$ & & \\
\hline \multirow[t]{2}{*}{$>20$} & 24 & $63.41 \pm 12.81$ & & \\
\hline & & & 0.855 & 0.492 \\
\hline \multicolumn{5}{|l|}{ Work type } \\
\hline On regular payroll & 75 & $67.09 \pm 14.07$ & & \\
\hline Contract & 104 & $65.41 \pm 10.50$ & & \\
\hline \multirow[t]{2}{*}{ Personnel agency } & 4 & $66.44 \pm 12.20$ & & \\
\hline & & & 3.411 & 0.035 \\
\hline
\end{tabular}

Table 5. Differences of resilience scores among obstetric nurses in general demographic data. 


\begin{tabular}{|c|c|c|c|c|c|c|}
\hline Project & $\begin{array}{l}\text { Total score of } \\
\text { resilience }\end{array}$ & Personal ability & $\begin{array}{c}\text { Sense of } \\
\text { control }\end{array}$ & $\begin{array}{l}\text { Spiritual } \\
\text { influence }\end{array}$ & $\begin{array}{c}\text { Endure negative } \\
\text { emotions }\end{array}$ & $\begin{array}{l}\text { Accept } \\
\text { changes }\end{array}$ \\
\hline Anxiety score & $-0.303^{\star *}$ & $-0.157^{\star}$ & $-0.320^{\star *}$ & -0.056 & 0.034 & -0.102 \\
\hline Support total score & $0.221 * \star$ & $0.189 *$ & $0.176^{\star}$ & 0.084 & $0.198^{\star \star}$ & $0.232^{* *}$ \\
\hline
\end{tabular}

Table 6. Correlation analysis of resilience and anxiety and social support of obstetric nurses. Note: ${ }^{*} P<0.05 ;{ }^{* *} P<0.01$.

\subsection{Correlation between resilience and anxiety and social support in obstetric nurses}

There were significant differences in total scores of resilience and total scores of anxiety and social support $(P<0.01)$, which were statistically significant (Table 6).

\section{Discussion}

\subsection{Differences in psychological resilience among obstetric nurses with different job types}

Table 5 shows that there is a difference in the score of work type and resilience score $(P<0.05)$, and the difference is statistically significant. This is consistent with the studies by domestic scholars such as Yang et al., ${ }^{13}$ Wang et al., ${ }^{14}$ and others. Different work types have different working states such as the contract nurses often shift, low welfare, occupation development is limited, promotion, go out the opportunity to study less, low return, high pay, psychological pressure ratio relative to the nurses more; therefore, nursing managers should pay attention to working conditions, different types of work of nurses, the balance of different types of work and nurses' mental state, should return in wages and benefits, income, job prospects, better maintenance of obstetric nurses' physical and mental health, so as to better optimize the quality of nursing service, with greater enthusiasm to work.

\subsection{Dimensions of resilience and anxiety scores were related to obstetric nurses}

Obstetric nurse resilience scores and anxiety scores were significantly negatively correlated $(P<0.01)$, namely the higher the resilience score, the lighter the anxiety symptom, and negatively related to personal ability and anxiety resilience of obstetric nurses $(P<0.05)$, namely the higher the ability of individual scores, the lighter the anxiety symptom; sense of control and obstetric resilience have a significant negative correlation with anxiety $(P<0.01)$, that is the better the sense of control, the lighter the anxiety symptom.
Resilience is difficult when individuals face great pressure,${ }^{15}$ and in the study by the domestic scholar Wang et al., ${ }^{16}$ it is shown that good adaptation ability can improve the resilience level of obstetric nurses, especially to enhance their ability to deal with problems and cultivate the sense of self-control, and can reduce the degree of depression and anxiety. Hospital managers should also pay attention to psychological health of obstetric nurses and make reasonable arrangements of nursing work to avoid the long time work overload, pay attention to emotional management of obstetric nurses, and reduce the incidence of anxiety of nurses.

\subsection{Dimensions of resilience in obstetric nurses were related to the total scores of social support}

The resilience score and social support score of obstetric nurses were positively related $(P<0.01)$, namely, the higher the degree of social support, the higher the score of psychological resilience; the resilience of individual ability score and total score of social support were positively correlated $(P<0.05)$, namely, the higher the degree of social support, the higher the score of resilience ability; the control the feeling score and social support score were positively related $(P<0.05)$, namely, the higher the degree of social support, the higher the score of psychological sense of control; elasticity to bear negative emotions and social support scores were significantly correlated $(P<0.01)$, namely the higher the score, the higher the score with negative emotional resilience; acceptance with the change score and the social support score were positively correlated $(P<0.01)$, namely, the higher the degree of social support, the higher the score to accept change. The higher the degree of social support, the greater the intensity of individual stress relief, the stronger the adaptability, which is consistent with the studies by the domestic scholar Si. ${ }^{17}$ Therefore, to improve the nurses' social support, with respect to friends and family, the hospital and the patient's understanding is helpful to improve their psychological resilience and mental health level, increase their social identity, and increase working enthusiasm. 


\section{Conclusions}

In summary, closely related to obstetric nurses' psychological resilience, social support, and anxiety, resilience can predict anxiety in different degree. Strengthening the level of resilience is an effective way to reduce anxiety and improve the obstetric nurses' psychological health level. Obstetric nurses should pay attention to enhance their level of resilience in the work, improve coping and resilience, maintain a good attitude, and at

\section{References}

1. Liu Yu, He GP. Progress of research on job stressors. Chin J Nurs. 2004;39:852-854 (in Chinese).

2. Zeng SX, Liu ZH, Shen P, Lin B, Xu MM. Correlation analysis of stressors, anxiety status and social support in obstetric nurses. PLA Nurs J. 2014;13:7-19, 31 (in Chinese).

3. Luthar SS, Cicchetti D, Becker B. The construct of resilience: A critical evaluation and guidelines for future work. Child Dev. 2000;71:543-562.

4. Hjemdal O, Friborg O, Stiles TC, Rosenvinge JH, Martinussen M. Resilience predicting psychiatric symptoms: A prospective study of protective factors and their role in adjustment to stressful life events. Clin Psychol Psychother. 2006;13:194-201.

5. Tugade MM, Fredrickson BL. Resilient individuals use positive emotions to bounce back from negative emotional experiences. J Pers Soc Psychol. 2004;86:320-333.

6. Matos PS, Neushotz LA, Griffin MT, Fitzpatrick JJ. An exploratory study of resilience and job satisfaction among psychiatric nurses working in inpatient units. Int J Ment Health Nurs. 2010;19:307-312.

7. Li XL, Zhang M. Study on the correlation between mental health and social support and job stress in oncology nurses in grade three first class hospitals. Depart Gen Nurs. 2014;27:2583-2585 (in Chinese).

8. Xiao SY. Theoretical basis and application of social support rating scale. J Clin Psychiatry. 1994;2:98100 (in Chinese). the same time, the nursing managers should pay attention to the social support of obstetric nurses, arrange more obstetric nurses' working group activities, talk of the trouble, create a harmonious working environment, and reduce the psychological pressure of obstetric nurses to improve the quality of obstetric nursing work.

\section{Conflicts of interest}

All contributing authors declare no conflicts of interest.

9. Li HF, Li P. Correlation analysis of psychological resilience and job burnout in psychiatric nurses. Chin Nurs Res. 2015;9:1063-1066 (in Chinese).

10. Connor KM, Davidson JR. Development of a new resilience scale: The Connor-Davidson Resilience Scale (CD-RISC). Depress Anxiety. 2003;18:76-82.

11. Zhang ZJ. Behavioral Medicine Scale Manual. Beijing: Chinese Medical Electronic And AudioVisual Publishing House; 2005 (in Chinese).

12. Qu HY, Gao Y. Nursing Psychology. Beijing: Science Press; 2016 (in Chinese).

13. Yang M. Study on the Correlation between Job Stress and Mental Health of Contract Nurses. Shanxi, China: Shanxi Medical University; 2008 (in Chinese).

14. Wang GM, Xie HF, Hu QM, Luo J. Study on the influencing factors of mental health status of psychiatric nurses. Chin J Nurs. 2014;28:3622-3624 (in Chinese).

15. Ren YX, Luo TZ, Zhou Y, et al. Correlation between nurses' resilience and job satisfaction and turnover intention in 10 general hospitals in Guangzhou. J Nurs. 2016;23:46-50 (in Chinese).

16. Wang WW, Pan LH, Wang J. Influence on the emotional management of obstetric nurses anxiety. Hosp Manage Forum. 2016;33:32-34 (in Chinese).

17. Si XY. Study on psychological resilience of nurses in hospital and related factors. Jilin, China: Jilin University; 2012 (in Chinese).

How to cite this article: Liu XX, Liu WH, Ping M, Li CY, Liu XY, Song P. Correlation between resilience and social support and anxiety in obstetric nurses. Front Nurs. 2018; 1: 311-316. https://doi.org/10.1515/fon-2018-0040. 